\title{
Pendampingan Pembuatan E-Learning Dengan Moodle Yang Dipadukan Dengan Software Matematika Geogebra Untuk Guru Matematika di SMP Muhammadiyah Se-Kecamatan Godean, Sleman, Yogyakarta
}

\author{
Syariful Fahmi ${ }^{1}$, Soffi Widyanesti Priwantoro ${ }^{2}$ \\ Universitas Ahmad Dahlan \\ Email: syarifulfahmi@gmail.com ${ }^{1}$,soffidyan@gmail.com²
}

\begin{abstract}
ABSTRAK
E-learning sebagai salah satu manfaat dari internet sangat mendukung untuk proses belajar mengajar. Oleh karena itu kemampuan penguasaan e-learning guru menjadi kata kunci dalam kegiatan e-learning dalam pendidikan. Penggunaan komputer untuk proses e-learning menggunakan moodle dan geogebra dalam belajar matematika memegang peranan penting sebagai media untuk menciptakan belajar mengajar yang efektif dan efisien bagi guru-guru matematika di SMP Muhammadiyah 1 Godean, SMP Muhammadiyah 2 Godean, SMP Muhammadiyah 1 Minggir, SMP Muhammadiyah 2 Minggir, SMP Muhammadiyah 1 Mlati. Adanya e-learning akan mempermudah guru dan siswa dalam menerima pelajaran matematika dan juga mempertinggi mutu belajar mengajar. Pendampingan dari pelaksanaan pelatihan IbM penggunaan e-learning dengan menggunakan moodle yang dipadukan dengan geogebra telah dilakukan bertempat di SMP Muhammadiyah 1 Godean dan menghasilkan media pembelajaran berbentuk e-learning. Pendampingan tersebut juga menghasilkan kesepahaman dengan kepala sekolah bahwa pelatihan bisa dilanjutkan untuk mata pelajaran lain.
\end{abstract}

Kata Kunci: E-learning, Moodle, Geogebra

\section{ABSTRACT}

E-learning as one of the benefits of the internet is very supportive for teaching and learning process. Therefore, the mastery ability of e-learning teacher become the key word in e-learning activity in education. The use of computers for the e-learning process using moodle and geogebra in learning mathematics plays an important role as a medium to create effective and efficient learning for teachers in SMP Muhammadiyah 1 Godean, SMP Muhammadiyah 2 Godean, SMP Muhammadiyah 1 Minggir, SMP Muhammadiyah 2 Minggir, SMP Muhammadiyah 1 Mlati. The existence of e-learning will facilitate teachers and students in receiving mathematics lessons and also enhance the quality of teaching and learning. The accompaniment of the implementation of IbM training using e-learning using moodle combined with geogebra was conducted at SMP Muhammadiyah 1 Godean and resulted in e-learning learning media. The mentoring also resulted in an understanding with the principal that the training could be continued for other subjects.

Keywords: E-learning, Moodle, Geogebra

\section{PENDAHULUAN}

Media pembelajaran dalam proses pembelajaran memegang peranan penting sebagai alat bantu untuk menciptakan proses belajar yang efektif. Terutama untuk belajar matematika yang sebagian siswa menganggap sebagai mata pelajaran 
yang sulit. Pembelajaran matematika memiliki fungsi sebagai sarana untuk mengembangkan kemampuan berpikir kritis, logis, kreatif, dan bekerja sama yang diperlukan siswa dalam kehidupan modern. Kompetensi tersebut diperlukan agar peserta didik dapat memiliki kemampuan memperoleh, mengelola, dan memanfaatkan informasi untuk bertahan hidup pada keadaan yang selalu berubah, tidak pasti, dan kompetitif (Peraturan Menteri Pendidikan Nasional nomor. 22 tahun 2006 tentang standar isi).

Salah satu teknik pembelajaran yang bisa digunakan dalam pembelajaran Matematika yang memberikan kesempatan kepada siswa untuk belajar kreatif, dan lebih aktif adalah dengan teknik pembelajaran menggunakan media pembelajaran dalam bentuk teknologi komputer berbasis e-learning yang di dalamnya terdapat program Moodle dan Geogebra sehingga diharapkan bahwa kemampuan berpikir kreatif matematika siswa dapat ditunjukkan dan meningkat. Fokus proyek Moodle adalah menyediakan bagi guru/ pendidik alat (tool) terbaik untuk mengelola dan mempromosikan kegiatan belajar. Moodle memiliki fitur yang memungkinkan untuk skala penyebaran yang sangat besar dan ratusan ribu siswa, namun juga bisa digunakan untuk sekolah dasar atau kegiatan belajar skala kecil lainnya. Banyak institusi menggunakannya sebagai platform mereka untuk melakukan kursus sepenuhnya online, sementara beberapa menggunakan- nya hanya untuk menambah kursus tatap muka (dikenal sebagai blended learning). Banyak pengguna Moodle suka menggunakan modul kegiatan (seperti forum, database dan wiki) untuk membangun komunitas kolaboratif untuk belajar intensif sekitar materi pelajaran (dalam tradisi konstruksionis sosial), ataupun menggunakan Moodle sebagai cara untuk menyampaikan konten untuk mahasiswa (seperti paket SCORM standar) dan menilai pembelajaran menggunakan tugas atau kuis.

Ada beberapa pertimbangan tentang penggunaan dynamic geometry software seperti Geogebra dalam pembelajaran matematika, khususnya geometri. Menurut David Wees (2009) Geogebra memungkinkan siswa untuk aktif dalam membangun pemahaman geometri. Program ini memungkinkan visualisasi sederhana dari konsep geometris yang rumit dan membantu meningkatkan pemahaman siswa tentang konsep tersebut. Ketika siswa menggunakan dynamic geometry software seperti Geogebra, mereka akan selalu selalu berakhir dengan pemahaman yang lebih mendalam pada materi geometri (putz, 2001) hal ini mungkin terjadi karena siswa diberikan representasi visual yang kuat pada objek geometri, di mana siswa terlibat dalam kegiatan mengkonstruksi sehingga mengarah kepada pemahaman geometri yang mendalam. Dengan menggunakan Geogebra, guru akan sangat terbantu dalam menyampaikan materi materi matematika sehingga siswa dapat 
mengkontruksi titik, vektor, ruas garis, garis, fungsi dan lain sebagainya kemudian dapat membantu siswa untuk memvisualisasikan bentuk bangun datar segi empat lebih rinci beserta ukuran-ukurannya sehingga mempengaruhi kemampuan berpikir kreatif siswa.

SMP Muhammadiyah 1 Godean sebagai salah satu sekolah tingkat pertama yang ada di kecamatan Godean yang telah memiliki laboratorium komputer. Namun keberadaan laboratorium komputer tersebut jarang sekali digunakan untuk proses belajar matematika yang mengarah ke e-learning. Salah satu guru matematika mengungkapkan bahwa guru di sekolah masih memiliki keterbatasan dalam memanfaatkan komputer sebagai alat bantu belajar mengajar matematika di sekolah tersebut. Kondisi di SMP Muhammadiyah 2 Godean lebih memprihatinkan lagi karena selain spesifikasi komputer yang tidak berubah sejak dulu, beberapa guru juga belum memiliki kemampuan dalam menggunakan komputer sebagai media pembelajaran. Adanya keinginan dari pihak sekolah, seperti yang diungkapkan oleh kepala sekolah SMP Muhammadiyah 1 Godean untuk dibantu dalam pemanfaatan komputer sebagai elearning atau alat bantu belajar matematika bagi siswa maupun guru.

Penggunaan komputer untuk proses e-learning menggunakan moodle dan geogebra dalam belajar matematika memegang peranan penting sebagai media untuk menciptakan belajar mengajar yang efektif dan efisien. Adanya e-learning akan mempermudah guru dan siswa dalam menerima pelajaran matematika dan juga mempertinggi mutu belajar mengajar. Pada pembelajaran matematika dengan menggunakan e-learning akan menjadikan siswa belajar melalui pengalaman dan berbuat sendiri. Hal ini akan menjadikan siswa memiliki daya serap matematika yang tinggi, yaitu diatas $70 \%$.

\section{Permasalahan Mitra}

Dari analisis situasi yang telah diuraikan diatas, dapat diidentifikasi permasalahan-permasalahan sebagai berikut:

1. Sekolah belum pernah melakukan proses balajar mengajar dengan menggunakan e-learning.

2. Guru tidak punya atau kurang waktu dalam membuat media pembelajaran berbasis e-learning.

4. Guru belum memiliki kemampuan dalam menggunakan moodle maupun geogebra.

\section{Tujuan Kegiatan}

Pengabdian ini bertujuan untuk:

1. Mendampingi guru-guru matematika dalam pembuatan media pembelajaran moodle yang dipadukan dengan menggunakan geogebra

2. Melakukan evaluasi bersama kepala sekolah terhadap pelatihan yang sudah dilakukan. 
METODE PELAKSANAAN

Pengabdian masyarakat ini dilakukan dengan terlebih dulu mencermati permasalahan yang ada di lapangan untuk mencari tahu bagaiamana pengetahuan peserta terhadap seluk beluk media pembelajaran, pengetahuan akan elearning, moodle dan software geogebra. Setelah diidentifikasi permasalahan yang ditemui maka selanjutnya diadakan workshop atau pelatihan bagi guru matematika di SMP Muhammadiyah se-kecamatan Godean dengan materi pembuatan elearning dengan program moodle, pembuatan materi pembelajaran matematika dengan geogebra serta pembuatan modul penggunaan media pembelajaran berbasis e-learning dengan menggunakan moodle dan geogebra. Pengabdian masyarakat ini dilakukan dengan menggunakan metode pendampingan, pelatihan dan penyampaian materi (ceramah). Materi pelatihan yang akan disampaikan adalah sebagai berikut:

1. Menggunakan Fungsi dasar moodle dan kegunaannya

2. Membuat domain e-learning dengan menggunakan moodle

3. Menggunakan fungsi dasar geogebra dan kegunaannya

4. Membuat poligon dan sudut menggunakan geogebra

5. Membuat persamaan garis.

6. Membuat Lingkaran dengan geogebra

7. Membuat persamaan garis singgung dengan memanfaatkan aplikasi geogebra.
8. Menggambar grafik fungsi aljabar.

9. Menggambar grafik fungsi kuadrat

10. Memanfaatkan fungsi slider dalam mentranformasikan grafik

11. Mengenalkan konsep limit dengan geogebra

12. Mengenalkan konsep integral tentu dan tak tentu dengan geogebra

13. Mengenalkan konsep trigonometri dengan geogebra

14. Mengenalkan konsep grafik fungsi trigonomteri dengan geogebra

15. Mengenalkan konsep statistika dengan geogebra

16. Mengenalkan konsep matriks dengan geogebra

17. Menggunakan geogebra untuk membuat animasi 3 dimensi pada Tabung

18. Menggunakan geogebra untuk membuat animasi 3 dimensi padaKubus

19. Menggunakan geogebra untuk membuat animasi 3 dimensi padaPrisma

20. Memasukan materi matematika yang telah dibuat dengan menggunakan geogebra kedalam moodle.

\section{HASIL DAN PEMBAHASAN}

Berikut hasil yang telah dicapai dalam pelaksanaan IbM penggunaan e-learning dengan menggunakan moodle yang dipadukan dengan software matematika geogebra untuk guru matematika di SMP 
Muhammadiyah se-kecamatan Godean, Sleman, Yogyakarta.

Kegiatan pelatihan dan pendampingan ini melibatkan dua orang dosen dan 4 mahasiswa dan bermitra dengan dua sekolah. Keanggotaan staf pengajar dipilih berdasarkan bidang keahlian yang dimiliki sehingga dapat menunjang kegiatan Pengabdian Masyarakat.

Pelatihan ini melibatkan guruguru matematika dari SMP Muhammadiyah 1 Godean sebanyak 3 guru, SMP Muhammadiyah 2 Godean sebanyak 1 guru, 4 guru dari SMP Muhammadiyah 1 Minggir, 1 Guru dari SMP Muhammadiyah 2 Minggir, 3 Guru dari SMP Muhammadiyah 1 Gamping, 3 Guru dari SMP Muhammadiyah 1 Mlati serta 2 guru dari SMP Muhammadiyah 2 Tempel. Pelatihan dilakukan sebanyak 12 kali dan dilakukan pendampingan sebanyak 3 kali. Kegiatan diawali dengan koordinasi dengan kepala sekolah dan guru-guru yang terlibat dan dilanjutkan dengan pelatihan dengan lokasi di laboratorium computer SMP Muhammadiyah 1 Godean. Pelatihan dilakukan setiap hari kamis, jumat, dan sabtu dengan melibatkan 4 mahasiswa sebagai asisten pelatihan. Pada tahap evaluasi dan monitoring Tim pelaksana mengukur keberhasilan peran guru dalam membuat e-learning untuk mendukung proses pembelajaran matematika serta dianalisis hambatan untuk keberlanjutan kegiatan tersebut. Dengan tersedianya laboratorium di SMP Muhammadiyah 1 Godean dapat membantu memfasilitasi kegiatan pengabdian masyarakat ini dengan memberikan kesempatan guru untuk belajar e-learning bagi guruguru matematika di SMP Muhammadiyah 1 Godean dan SMP Muhammadiyah 2 Godean.

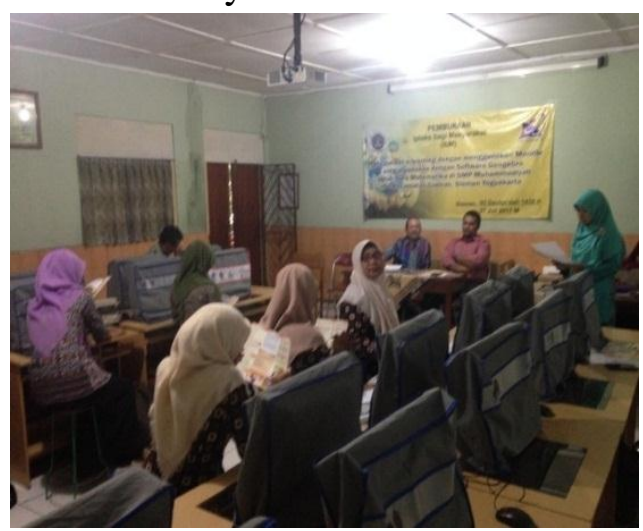

Gambar 1 Dokuentasi pelaksanaan pelatihan

Berikut ini adalah tampilan hasil karya guru dari SMP Muhammadiyah 1 Godean dengan alamat web: uye.gnomio.com.

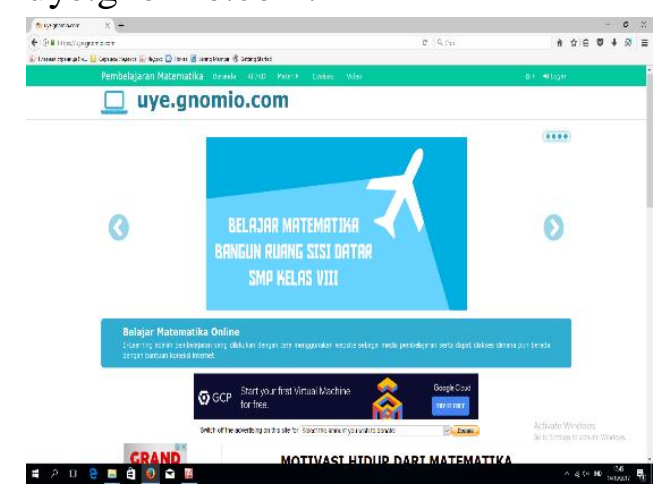

Gambar 2. Tampilan hasil karya guru

Pendampingan dilakukan sebanyak tiga kali pada guru-guru di SMP Muhammadiyah 1 Godean. Dari pendampingan yang telah dilakukan, guru mengungkapkan bahwa mereka sangat menikmati membuat materi matematika dalam geogebra, namun ketika menggunakan moodle para guru masih mengalami kesulitan sehingga pendampingan yang 
dilakukan bisa membantu guru untuk memasukan materi geogebra kedalam moodle. Selain pendampingan juga dilakukan evaluasi bersama dengan kepala sekolah. Sekolah sangat mengapresiasi pelatihan yang sudah dilakukan dan berharap bisa dilakukan juga pelatihan untuk guruguru mata pelajaran lain.

\section{SIMPULAN}

Berdasarkan kegiatan yang telah dilakukan dapat disimpulkan:

1. Pelaksanaan pelatihan sangat mendukung kegiatan belajar mengajar guru di kelas.

2. Guru-guru sangat bersemangat dalam melakukan pelatihan

\section{DAFTAR PUSTAKA}

Andraphanova, N. 2015.Geometrical similarity transformations in Dynamic Geometry Environment Geogebra. European Journal of Contemporary Education, 12(2):116-128

Bako, M. 2003. Different Projecting Methods In Teaching Spatial Geometry. European Research in Mathematics Education III

Dindyal, J. 2015. Geometry in The Early Years: A Commentary. ZDM Mathematics Education. 47: 519-529

Del Grande, J. 1990. Spatial Sense. The Arithmetic Teacher, 37(6): 14-20

Guven, B \& Kosa, A. 2008. The Effect of Dynamic Geometry Software On Student Mathematics Teachers' Spatial Visualization Skills. The Turkish
Online Journal of Educational Technology, 7 (4): 1-8

Guzel, N \& Sener, E. 2009. High School Students' Spatial Ability and Creativity in Geometry. Procedia Social and Behavioral Sciences 1: 1763-1766

Hmelo. S. 2004. Problem-Based Learning: What and How Do Student Learn?. Educational Psychology Review, 16(3): 235266

Hudojo, H. 1988. Mengajar Belajar Matematika, Departemen Pendidikan dan Kebudayaan Jakarta.

Hung, W., David H. J., \& Rude Liu. 2008. "Problem-based learning". Handbook of research on educational communications and technology, 3: 485-506.

I Kadek S, I Dewa Made. 2014. ELearning Berbasis Moodle. Yogyakarta: Graha Ilmu

Kurtuluu, A \& Uygan, C. 2010. The Effects Of Google Sketchup Based Geometry Activities And Projects On Spatial Visualization Ability Of Student Mathematics Teachers. Procedia Social and Behavioral Sciences, 9: 384-389

Kuzniak.A \& Rauscher, J.C. 2011.How do teachers' approaches to geometric work relate to geometry students' learning difficulties?. Educ Stud Math, 77:129-147

Mulligan, J. 2015.Looking Withinand Beyond The Geometry Curriculum: Connecting Spatial Reasoning To Mathematics Learning. ZDM Mathematics Education, 47:511-517

NCTM (National Council of Teachers of Mathematics). 2000. Principles and Standards for School Mathematics. Amerika Serikat: NCTM. 
Richardson, K \& Stein, C. 2008.

Developing Spatial Sense And

Communication Skills.

Mathematics Teaching In The

Middle School, 14(2): 101-107

Rajagopal, S dkk.2015.Attitude of Secondary Students towards the Use of Geogebra in Learning Loci in Two Dimensions. International Education Studies, 8(13): 27-32

Rohaeti, et al. 2014 .

Enhancingstudents'

Mathematical Logical Thinking

Ability and Self-Regulated

LearningThroughProblem-Based

Learning. International Journal of Education, 8(1): 54-63

Saha, R. A dkk. 2010. "The Effects of

Geogebra on Mathematics

Achievement: Enlightening

Coordinate Geometry Learning".

Procedia Social and Behavioral

Sciences, 8 : 686-693

Tandililing, E. 2011. "The

Enhancement of Mathematical

Communication and Self-

Regulated Learning of Senior

High School Students

ThroughPQ4R Strategy

Accompanied by Refutation Text

Reading”. Proceding of

International Seminar and the

Fourth National Conference on

Mathematics Education 2011. 917-928

Tuluk, G. 2013. “Meaningful learning approach in dynamic and interactive learning environment: plan for a geometry class on point, line, surface, object". International Journal Of Academic Research, 5 (4): 384398 